\title{
A Quantitative Comparison of Heavy Metal Concentrations in the Soils on Two Rocky Mountain West Tribal Reservations
}

\author{
Raquel Robello ${ }^{1}$, Kaylin Lake ${ }^{1}$, Rod Handy ${ }^{1}$, Darrah Sleeth ${ }^{1}$, Scott C. Collingwood ${ }^{1}$, and \\ Camie Schaefer ${ }^{1}$ \\ ${ }^{1}$ University of Utah, Salt Lake City, UT, USA \\ DOI: https://doi.org/10.47611/jsr.v10i1.1182
}

\section{$\underline{\text { ABSTRACT }}$}

Native Americans have experienced a long history of environmental injustice, including natural resource exploitation and commercial activity with environmental impacts. A community-based participatory research (CBPR) approach was used to partner with two Rocky Mountain West reservations to conduct pilot-level assessments of potential soil contamination by heavy metals. The Community Advisory Board in conjunction with the research team selected residential areas and community sites for sampling. Samples were obtained, transported to a laboratory for dehydration and sieving, and were analyzed with a handheld X-ray fluorescence (XRF) tool for the presence of 24 heavy metals. Heavy metals concentrations were compared between reservations and were found to be statistically different from one another. Findings were also compared to levels recommended by the Environmental Protection Agency (EPA) and World Health Organization (WHO) to determine possible hazards to human health. Concentration of Sr, Rb, and Th were well above acceptable EPA levels and require further analysis. High localized Pb levels were found in one area, while Hg levels were found close to EPA standards. CBPR was essential to understanding preliminary contamination patterns. In conclusion, even reservations with similar geographies and histories present with unique contaminations and require individualized study to determine possible environmental mitigation.

\section{Introduction}

Environmental injustices and inequality of Native Americans

Environmental injustice, or environmental risk that is disproportionately experienced by certain groups, has been increasingly linked to Native American health disparities in the United States [1,2]. Native American communities have experienced profound environmental injustice, in part due to exploitation of their land for natural resources, including hard rock mining and other anthropogenic sources such as nuclear waste, oil and gas operations, and hazardous waste [3-5]. These sources vary in length from generations-long periods of exposure to other, shorter-lived projects; the duration of a hazardous project may influence in overall contamination of land and human health [3,4]. Nine federally recognized tribes live in the states of Colorado, Utah, and Wyoming (hereafter referred to as the Rocky Mountain West), regions that have abundant mineral deposits that have been mined extensively for metals such as gold, silver, copper, lead, and uranium that left behind contaminated soil and waters in their wake [6,7]. Additional environmental concerns stem from sources such as the transportation of mining material, tailing storage, smelting, insecticides, automobile exhaust, and illegal dumping of materials such as petroleum, radioactive waste, and household appliances [8]. 
Native Americans experience high rates of cardiovascular disease, diabetes, chronic liver disease, lower respiratory disease, and malignant neoplasm, all of which contribute to an estimated life expectancy of 5.5 years lower than all U.S. races $[9,10]$. While many of these conditions have been typically attributed to socioeconomic factors (e.g., poverty, smoking status, access to medical care), both researchers and Native American communities have both raised concerns regarding environmental health, especially given how traditional Native American life is closely intertwined with the environment. Causal relationships between environmental contaminants and health disparities are difficult to establish, but what is known is that factors such as pre-existing medical conditions, nutritional intake, and smoking status affect the absorption and excretion of toxins [13-16].

Studies such as those by Lewis et al. [3] have underlined the far-reaching scope of environmental contamination in tribal communities, while other studies have examined specific forms of contamination in the form of local plants [17], animals and fish used for food [16], and drinking water/local wells [18], and air quality [19]. Works such as these represent a paradigm shift in environmental health studies among Native American populations, as traditional risk assessments have been criticized for failing to encompass the unique nature of Native American life [20]. Native American populations are also especially vulnerable to environmental contaminates such as heavy metals, as many Native American communities' practice tribal ecological knowledge (TEK), a framework that conceptualizes life as a relationship with the earth, including time spent in nature, historic knowledge of a place and its environment, and the cultivation, consumption, and ceremonial use of plants [21].

\section{Risks posed by heavy metal contamination in Native American communities}

TEK directs research to activities such as soil contamination due to the role toxins may potentially play in food systems and medicinal or ceremonial plants [22,23]. One particular form of soil contamination linked to anthropogenic sources on and around reservations is contamination with "heavy metals" - an ill-defined category of metals and metalloids that can naturally occur in the earth's crust in varying degrees, but in higher levels are associated in literature with potential toxicity and both short- and long-term health effects. Anthropogenic contamination has been commonly associated with the following heavy metals in levels dangerous to human health: lead $(\mathrm{Pb})$, chromium $(\mathrm{Cr})$, arsenic (As), zinc $(\mathrm{Zn})$, cadmium $(\mathrm{Cd})$, copper $(\mathrm{Cu})$, and mercury $(\mathrm{Hg})$ [8]. Health effects from exposure to the metals include serious neurological, neurological, reproductive, gastrointestinal, kidney, hematological and carcinogenic effects $(\mathrm{Pb}$, $\mathrm{Cu}$, As, among others), oxidative stress ( $\mathrm{U}, \mathrm{As}, \mathrm{Zn}$ ), and adverse effects to cellular components, including the cell membrane mitochondria, and enzymes involved in metabolism and cellular repair processes (rubidium [Rb], strontium [Sr], and thorium [Th]) [24-29].

Heavy metals do not undergo microbial or chemical degradation, leading to persistent concentrations that can then percolate into ground water or bioaccumulate into plants, therefore creating a prolonged exposure for communities that live on or around contaminated soils [8]. Exposure routes include inhalation of heavy-metal laden dust (to which children are especially vulnerable), direct ingestion of contaminated soils, or consumption of food grown in contaminated soils, as plants may absorb heavy metals from soil of from sedimentation of metal particulates from the air onto the leaves of the plants $[3,30]$. Soil health, in conjunction with clean air and water, represent not only means to improve Native American health disparities, but as a means to restore traditional lifestyles [12,23]. Understanding the roles that these elements may play in TEK is key to environmental health among Native American populations.

\section{Environmental assessment and research}

This study conducted a community-wide soil survey in two Native American reservations in the Rocky Mountain West region of the U.S. Tribal governance on both reservations expressed a desire to remain anonymous in initial scientific publications; therefore, the reservations will be referred to as Frontier Reservation \#1 (FR1) and Frontier Reservation \#2 (FR2) throughout the manuscript. 
The goals for this study were threefold: first, to establish a sustainable partnership with the tribal communities; second, to work with tribal members to characterize the presence of heavy metals in soils within the community; and finally, to lay the foundation for larger, community-wide environmental assessments and future interventions. We therefore sought to determine if both communities were experiencing similar patterns of contamination and could jointly participate in remediation and educational initiatives. We hypothesized that based on regional differences in geologic provenances of soils (that impact natural background levels of heavy metals), the varying durations of contamination, and inconsistency of previously implemented environmental remediation, the presence of heavy metal contaminants in soils would vary even the sources of contamination were identical.

\section{Methods}

Community-wide soil screening took place within the larger context of a community-based participatory research (CBPR) project consisting of researchers and tribal members, tribal authorities, and key stakeholders on each reservation. CBPR functions as a true partnership in which both partners mutually agree upon priorities, research protocol, and dissemination of the results [32], and has been successfully deployed in other environmental health projects with Native Americans [18,23]. In addition, ownership of data is retained among relevant stakeholders, something that is especially key given the long history of scientific exploitation of Native American populations [20]. This particular CBPR was an important initiative in establishing tribal ownership of their health and land assessment, as well as creating trust between the University of Utah and the individual communities.

The initial step in forming the partnership was outreach to tribal leadership of each reservation. Individual members who indicated interest in the project agreed to serve on a Community Advisory Board (CAB) intended to facilitate the collaboration between the community and the research team. Two separate CABs were formed in each community to ensure that individual community concerns were prioritized. The composition of the CABs varied slightly between each board, but generally included tribal leaders, members from housing, environment, and health departments, and key community members, such as elders, parents, and educators. The aims and scope of the research were developed in collaboration with the CABs for both tribes. This particular project was partially formed in response to concerns community members had previously expressed regarding heavy metal soil contamination. The CABs and research team agreed that results would be disseminated to community leadership and the researchers would help facilitate resolution of any issues found in the course of sampling.

Following the project conceptualization, $\mathrm{CAB}$ members advocated for the research with their tribal councils and elder leadership. Two separate tribal resolutions (one for each community), which expressed legislative approval and community consensus on the value of the project, were obtained. While both tribal councils expressed a desire to remain anonymous in publication (as previously discussed), they were congruent in their desire to create a project that involved active members of their respective communities. The tribal council was therefore involved in determining the scope of the research, recruiting participants, disseminating results to the community, and addressing any issues that arose from the results. Community-reported concerns about heavy metals in the soil were a key motivating factor in the design of this project.

Members of the $\mathrm{CAB}$ and the research team established early on that in order to obtain a holistic understanding of heavy metal contaminants, both residential and community areas would need to be sampled. Tribal leaders and the $\mathrm{CAB}$ guided selection of community sites based on criteria of 1) those believed to be potentially contaminated due to current complaints or the historical presence of contaminants and 2) were frequented by tribal community members. These sites included tribal headquarters, preschools, playgrounds, community centers, and powwow grounds. Residential sites were collaboratively selected to establish a spectrum of households located across the reservation, as both reservations were large and sometimes sparsely populated in areas.

Household recruitment took place in mid-March of 2018 for Frontier Reservation \#1 and during the months of October and November of 2018 for the Frontier Reservation \#2. The CAB for both locations shared a list of community members interested in participating, who were then contacted by members of the research team for 
engagement. Households were eligible to participate if members 1) currently resided on the reservation, 2) the household contained an individual age 18+, and 3) an adult member (18+) of the household voluntarily consented to allow collection of representative soil samples from the outdoor area around the residence. In total, 11 households on Frontier Reservation \#1 and 10 households on Frontier Reservation \#2 were recruited.

Soil samples were collected in March 2018 for FR1 ( $\mathrm{n}=18)$, and in October and November 2018 for FR2 (n = 34). Procedures for soil sample collection were identical for each community, unless otherwise noted. At each sampling location (residential or community), up to four equidistant samples were taken between 1.5 - 5 meters apart to avoid localized contamination. Whenever possible, samples were taken from areas with evidence of human activity (e.g., gardening, children's play areas); otherwise, locations were selected based on frequency of use by the community as suggested by members of the CAB. Topsoil from residential and public areas (within $5-8 \mathrm{~cm}$ of the surface) were collected with a metal hand trowel and was composited at the scene in a polyethylene bag. Researchers were careful not to collect paint chips and other noticeable solid objects that might contaminate the sample. Composite samples were labeled with the sample location and date and were transported to a laboratory.

Each soil sample was then dehydrated, homogenized, and sieved to $125 \mu \mathrm{m}$ to achieve a uniform particle size. Processed soil samples were analyzed for 24 different heavy metals using a portable Thermo Fisher Scientific Xray Fluorescence (XRF) field analyzer (Thermo Fisher Scientific Inc., Waltham, Massachusetts). The XRF analyzer was selected as the analytical instrument, as it is both a cost-effective tool and one that had previously been validated by the Environmental Protection Agency (see EPA method 6200) for determining heavy metal concentrations in soil and sediment [36]. The samples were analyzed between 60-90 seconds depending on individual researcher work practices. Results below the limit of detection (LOD) were replaced by $\mathrm{LOD} / \sqrt{2}$ for statistical analysis.

Follow-up testing was conducted for one area of the FR1 in June 2018 in response to dramatically high concentrations of $\mathrm{Pb}$ in samples taken from one community site. Topsoil samples (depth $=7 \mathrm{~cm}$ ) were collected at progressive intervals of $0.3 \mathrm{~m}$ away from each wall of the building (see Figure 1 ). To determine the depth of $\mathrm{Pb}$ contamination, one sample was obtained at a depth of $15 \mathrm{~cm}$ on the west side. Soil samples were processed and analyzed in the laboratory using methods previously described above.

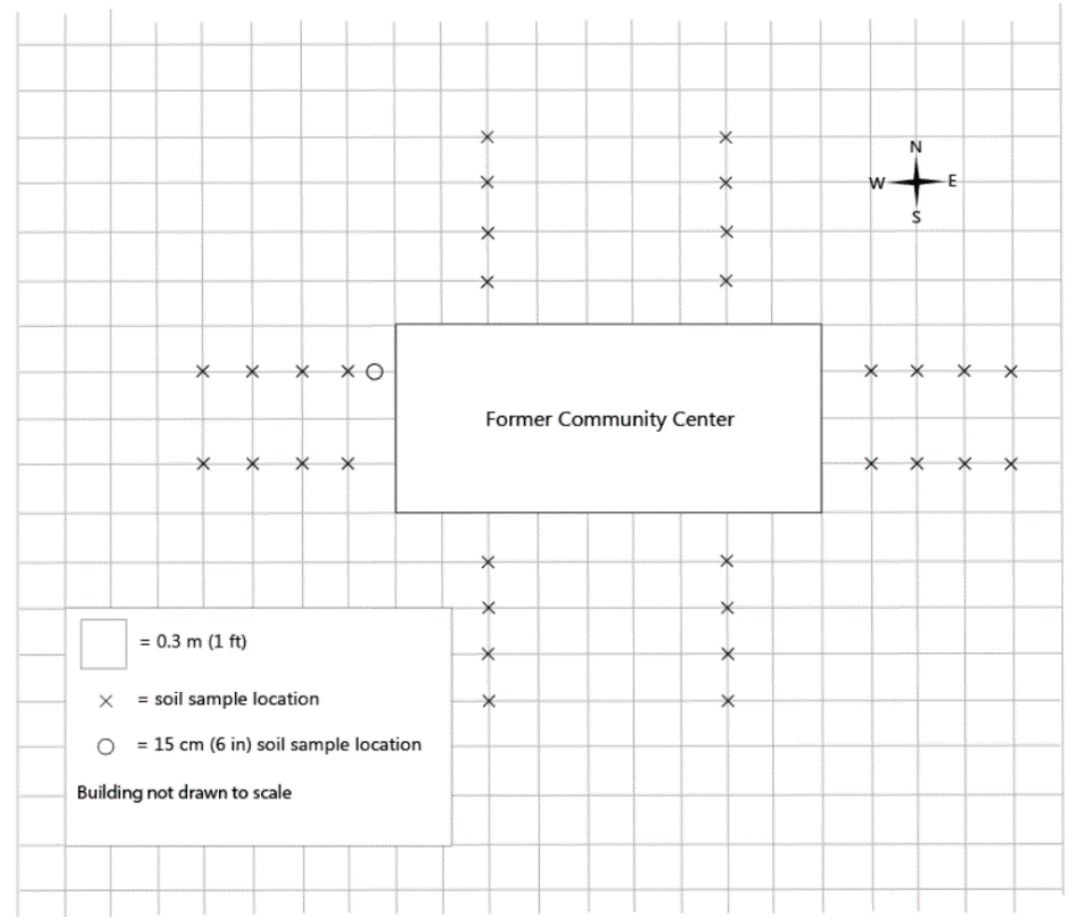

Figure 1. Former Community Center Sampling Locations. 
Prior to statistical analysis, reference concentrations from regulatory agencies were selected for comparison target values. Thresholds from regulatory and public health agencies including the EPA, United States Geological Survey (USGS), and the World Health Organization (WHO) were identified. The most relevant threshold values were the EPA Soil Screening Levels (SSL), as they have been developed for site evaluation with the end goal of promoting human health [34]. If an SSL was unavailable, Resource Conservation and Recovery Act (RCRA) levels, which were created to mandate waste management, were used (40.CFR.261.24) [35]. When neither SSL nor RCRA levels were available, recommendations from the USGS [36] or the World Health Organization (WHO) were used [37]. If there was a discrepancy between standards, the lowest value was selected.

\section{Statistical Analysis}

Statistical analysis was conducted in Excel® (Microsoft, Redmond, Washington) and IHSTAT, an Excel® based tool available through the American Industrial Hygiene Association [25]. Descriptive statistics were calculated for those elements that had $\geq 75 \%$ of values above the LOD. To determine normality, a w-test was conducted in IHSTAT. A Wilcoxon rank-sum test was performed to determine if the distribution of metal concentrations in the soil were statistically different between the two reservations, based on an alpha level of 0.05 .

To determine if the concentrations measured in the communities were consistent with those resulting from the particular geology, soil deposition, and historic use of land resources in the West, an ANOVA statistical test was performed to compare Western United States area samples taken by the USGS to samples collected in FR1 and FR2.

\section{Results}

A total of 11 heavy metals had $75 \%$ of values above the XRF LOD and therefore were analyzed. Heavy metal concentrations for each tribal community, as well as results of Wilcoxon Rank Sum test and ANOVA tests are provided in Table 1. Some variation was found between the two reservations, with statistically significant $p$-values $(p<0.05)$ found for $\mathrm{Zr}$, Th, Ti, Ca, and Fe (Figure 2).

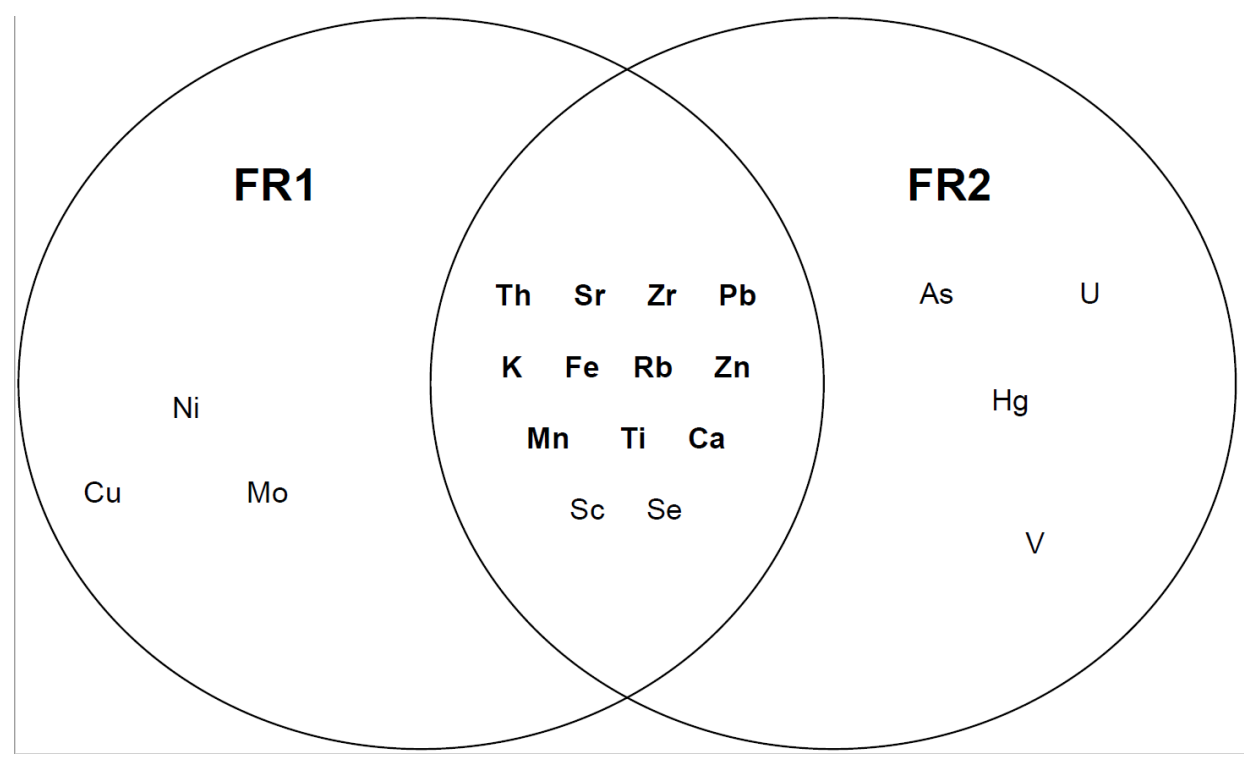

Figure 2. Visual representation of metals found within FR 1 and FR2 and in common. Bolding denotes metals found above $>75 \%$ above the LOD. 
The median concentrations for all 11 heavy metals were higher in both frontier communities compared to natural average area levels recorded by the USGS; however, these did generally not exceed recommended values. In both communities, Sr and Th both were found to exceed the EPA recommended levels of 2-12 ppm and 0.2 - 100 $\mathrm{mg} / \mathrm{kg}$, respectively (Figures 4-5). Values in excess of EPA recommended levels of Rb were found in $100 \%$ of FR1 and $32 \%$ of FR2 samples (Figure 6).

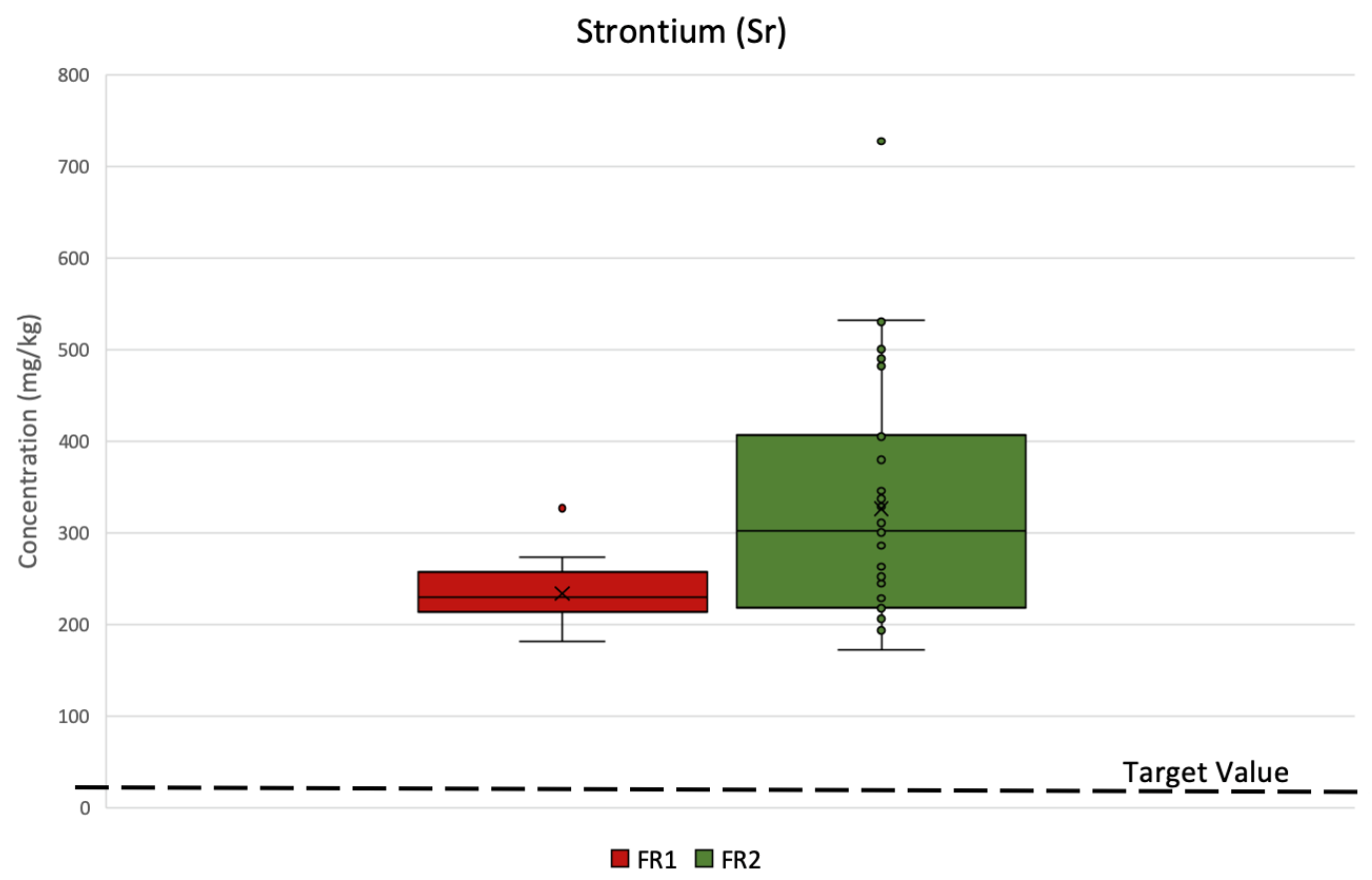

Figure 3. Strontium (Sr) levels of FR1 and FR2 compared to target values.

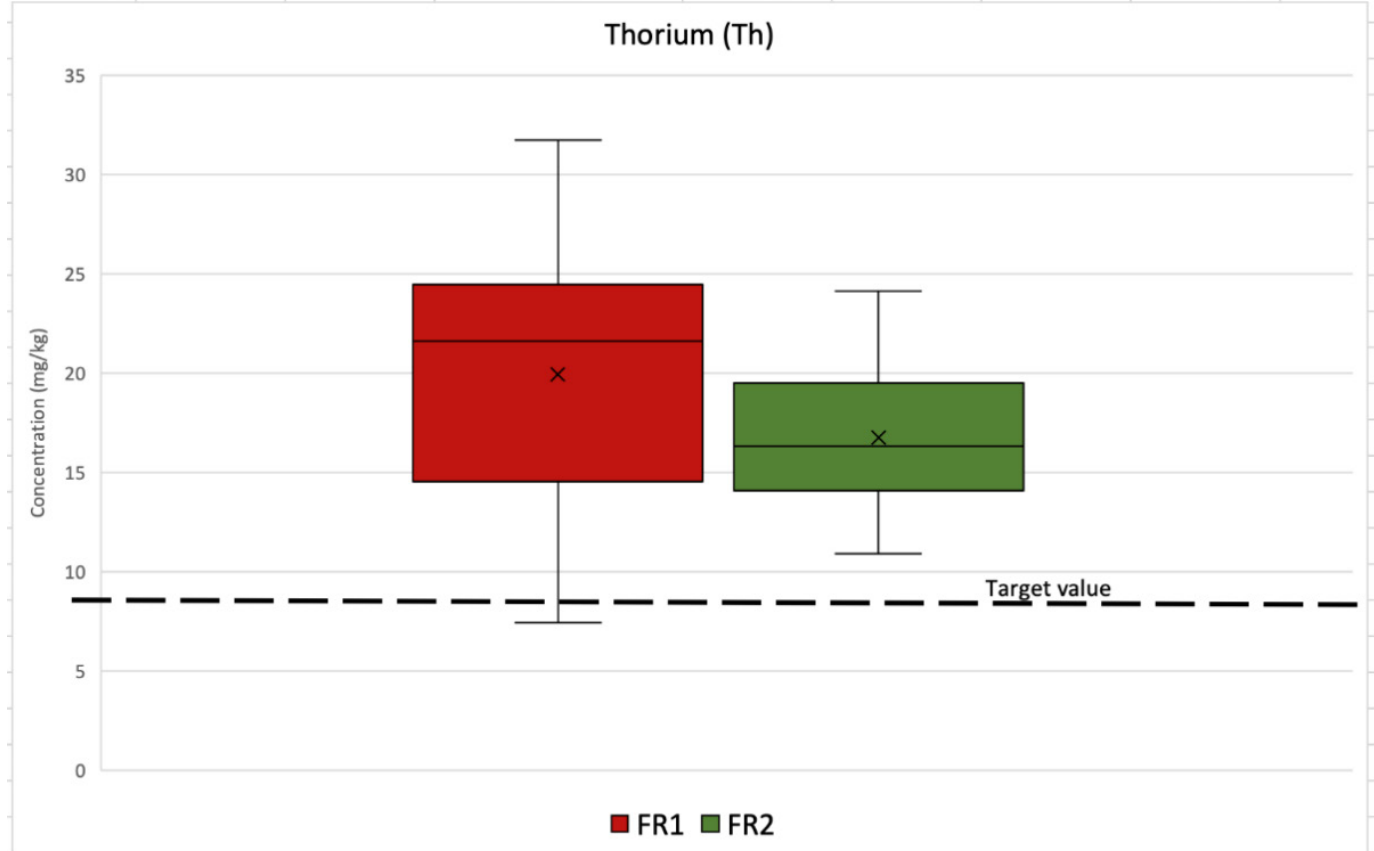

Figure 4. Thorium (Th) levels of FR1 and FR2 compared to target values. 


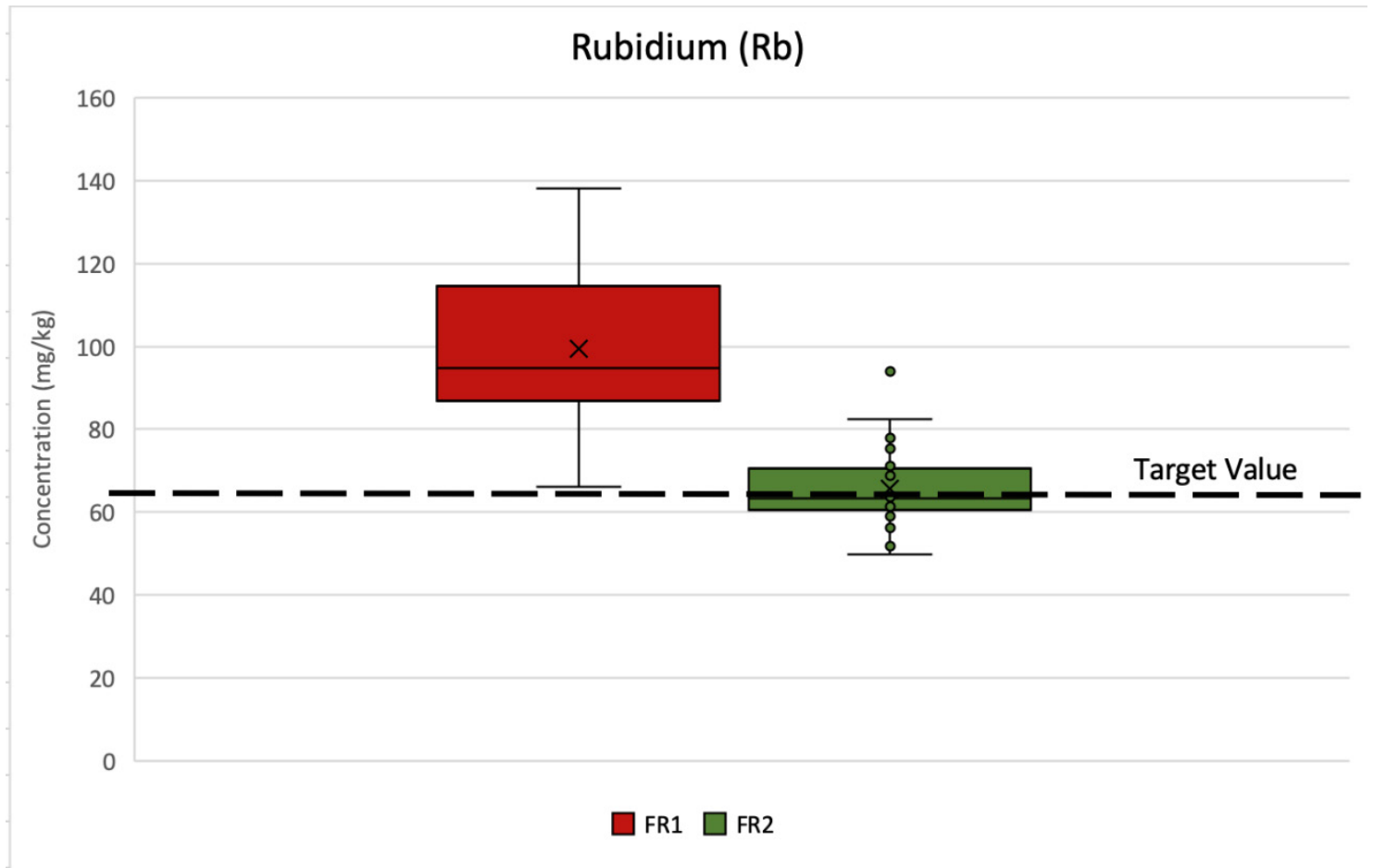

Figure 5. Rubidium $(\mathrm{Rb})$ levels of FR1 and FR2 compared to target values.

FR1, while not statistically different from FR2 in overall lead levels (i.e., generally at or below targeted values), was found to contain $5099.7 \mathrm{ppm}$ of $\mathrm{Pb}$ near the former community center. This value is 12 times the EPA residential soil limit of $425 \mathrm{mg} / \mathrm{kg}$. Results from the follow-up sampling determined that the lead contamination was localized within 0.6 meters from the building walls (see Figure 7 ) and confined to the topsoil ( $7 \mathrm{~cm}$ deep).

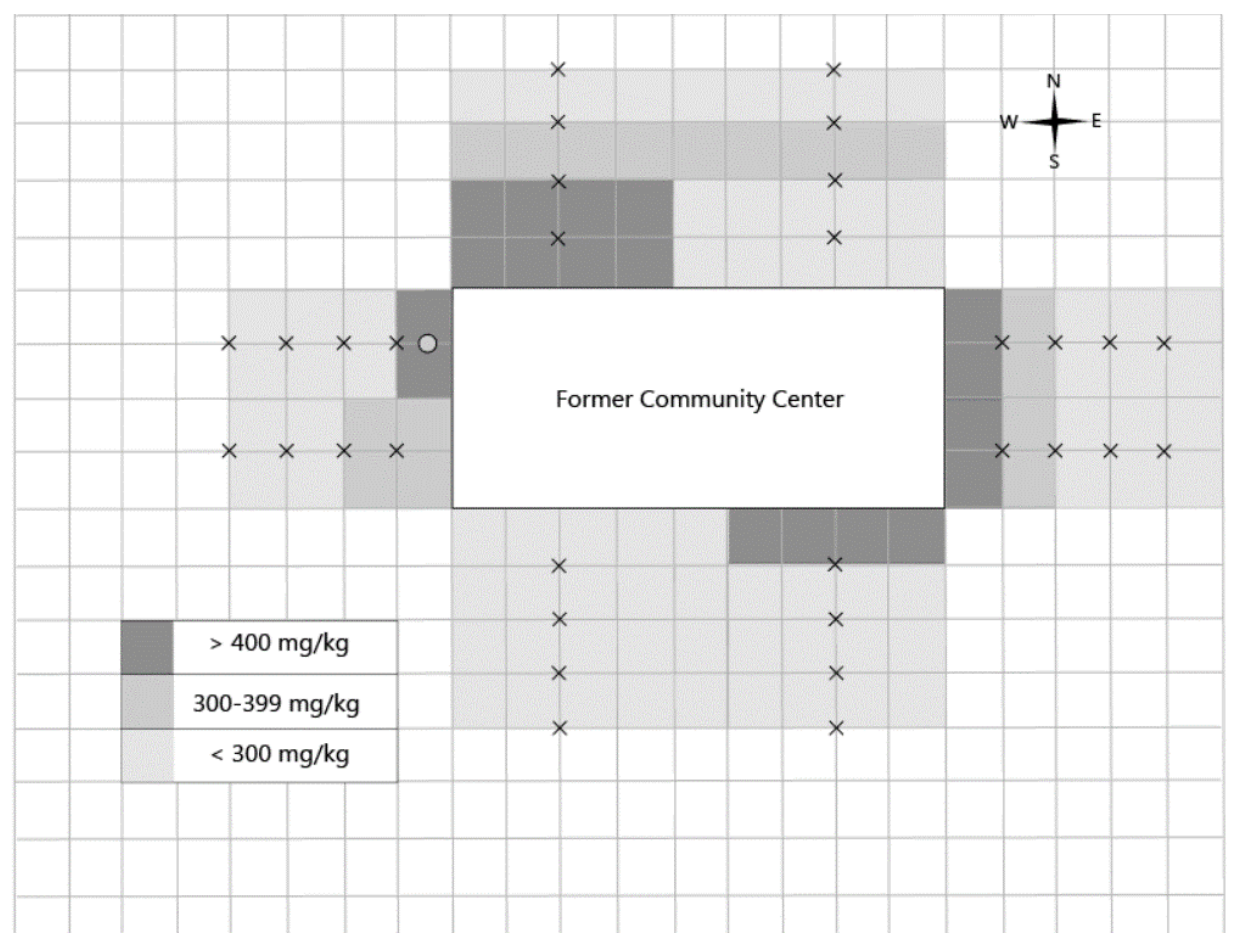

Figure 6. Lead Contamination Surrounding Former Community Center in FR1. 
Table 1. Overview of results from all tests performed: descriptive statistics for heavy metals with $>75 \%$ reading over the LOD for FR1 and FR2, p-value comparisons of means between communities, comparisons to soil standards, and comparisons between communities and average Western soil sample values (WSV). For target values EPA values are presented with “*”, WHO is represented by a “॰”, and USGS values are represented with a " $\therefore$ ”

\begin{tabular}{|c|c|c|c|c|c|c|c|c|c|}
\hline & $\begin{array}{c}\text { Mean } \pm \text { SD } \\
(\mathrm{mg} / \mathrm{kg})\end{array}$ & $\begin{array}{c}\text { Me- } \\
\text { dian } \\
(\mathrm{mg} / \mathrm{kg} \\
)\end{array}$ & $\begin{array}{c}\text { Max } \\
(\mathrm{mg} / \mathrm{k} \\
\mathrm{g})\end{array}$ & $\begin{array}{c}\text { Geometric } \\
\text { Mean } \pm \\
\text { SD } \\
(\mathrm{mg} / \mathrm{kg}) \\
\end{array}$ & $\begin{array}{c}\text { p-value } \\
\text { between } \\
\text { commu- } \\
\text { nities } \\
\end{array}$ & $\begin{array}{c}\text { Tar- } \\
\text { geted } \\
\text { value } \\
\text { (mg/kg) }\end{array}$ & $\begin{array}{c}\% \\
\text { above } \\
\text { target }\end{array}$ & $\begin{array}{c}\text { Mean } \\
\text { WSV } \\
(\mathrm{mg} / \mathrm{kg})\end{array}$ & $\begin{array}{c}\text { p-value be- } \\
\text { tween } \\
\text { WSV and } \\
\text { FR1/FR2 } \\
\end{array}$ \\
\hline \multicolumn{10}{|c|}{ Zirconium (Zr) } \\
\hline FR1 & $\begin{array}{c}418.98 \pm \\
79.15\end{array}$ & 434.36 & $\begin{array}{c}527.2 \\
8\end{array}$ & $411 \pm 1.23$ & \multirow{2}{*}{0.08} & \multirow{2}{*}{$\begin{array}{c}60- \\
2000 *\end{array}$} & 0.0 & \multirow{2}{*}{160} & 0.02 \\
\hline FR2 & $\begin{array}{c}499.47 \pm \\
160.95\end{array}$ & 489.5 & $\begin{array}{c}848.0 \\
8\end{array}$ & $437 \pm 1.41$ & & & 0.0 & & \\
\hline \multicolumn{10}{|c|}{ Strontium (Sr) } \\
\hline FR1 & $\begin{array}{c}234.14 \pm \\
34.56\end{array}$ & 229 & $\begin{array}{c}326.5 \\
7 \\
\end{array}$ & $232 \pm 1.15$ & \multirow{2}{*}{0.0179} & \multirow{2}{*}{$0.2^{\bullet}$} & 100 & \multirow{2}{*}{100} & 0.005 \\
\hline FR2 & $\begin{array}{c}326.29 \\
\pm 130.10\end{array}$ & 302 & $\begin{array}{c}727.6 \\
2\end{array}$ & $305 \pm 1.45$ & & & 100 & & \\
\hline \multicolumn{10}{|c|}{ Rubidium (Rb) } \\
\hline FR1 & $\begin{array}{c}99.42 \pm \\
19.57\end{array}$ & 94.7 & $\begin{array}{c}138.1 \\
1\end{array}$ & $\begin{array}{c}97.6 \pm \\
1.22\end{array}$ & \multirow[t]{2}{*}{$<0.0001$} & \multirow[t]{2}{*}{$66^{*}$} & 100 & \multirow[t]{2}{*}{69} & $<0.0001$ \\
\hline FR2 & $65.65 \pm 9.3$ & 63.4 & 93.91 & $65.1 \pm 1.15$ & & & 32.4 & & \\
\hline \multicolumn{10}{|c|}{ Zinc $(\mathbf{Z n})$} \\
\hline FR1 & $\begin{array}{c}184.12 \pm \\
402.94\end{array}$ & 93.1 & $\begin{array}{c}1796 . \\
34 \\
\end{array}$ & $103 \pm 2.12$ & \multirow{2}{*}{0.013} & \multirow{2}{*}{$23,000 *$} & 0.0 & \multirow{2}{*}{55} & 0.33 \\
\hline FR2 & $\begin{array}{c}81.10 \pm \\
55.98 \\
\end{array}$ & 63.4 & $\begin{array}{c}320.1 \\
4 \\
\end{array}$ & $\begin{array}{c}69.7 \pm \\
1.68 \\
\end{array}$ & & & 0.0 & & \\
\hline \multicolumn{10}{|c|}{ Thorium (Th) } \\
\hline FR1 & $\begin{array}{c}19.95 \pm \\
7.53\end{array}$ & 21.59 & 31.72 & $\begin{array}{c}18.3 \pm \\
1.57\end{array}$ & \multirow{2}{*}{0.047} & \multirow{2}{*}{$8 *$} & 83.3 & \multirow{2}{*}{9.1} & 0.04 \\
\hline FR2 & $16.75 \pm 3.6$ & 16.32 & 24.11 & $\begin{array}{c}16.4 \pm \\
1.24 \\
\end{array}$ & & & 100 & & \\
\hline \multicolumn{10}{|c|}{ Manganese (Mn) } \\
\hline FR1 & $\begin{array}{c}531.91 \pm \\
89.23\end{array}$ & 549.93 & $\begin{array}{c}707.7 \\
3 \\
\end{array}$ & $525 \pm 1.19$ & \multirow{2}{*}{$<0.0001$} & \multirow{2}{*}{$1800 *$} & 0.0 & \multirow{2}{*}{380} & $<0.0001$ \\
\hline FR2 & $\begin{array}{c}382.75 \pm \\
88.59\end{array}$ & 389.09 & $\begin{array}{c}592.5 \\
5 \\
\end{array}$ & $371 \pm 1.30$ & & & 0.0 & & \\
\hline \multicolumn{10}{|c|}{ Lead $(\mathbf{P b})$} \\
\hline FR1 & $\begin{array}{c}302.34 \pm \\
1197.33 \\
\end{array}$ & 20.67 & $\begin{array}{c}5099 . \\
67 \\
\end{array}$ & $\begin{array}{c}19.6 \pm \\
5.53 \\
\end{array}$ & \multirow{2}{*}{0.005} & \multirow{2}{*}{$\begin{array}{l}400- \\
425 *\end{array}$} & 5.6 & \multirow{2}{*}{17} & 0.37 \\
\hline FR2 & $\begin{array}{c}13.05 \\
\pm 14.01 \\
\end{array}$ & 11.40 & 89.20 & $\begin{array}{c}10.6 \pm \\
1.75\end{array}$ & & & 0.0 & & \\
\hline \multicolumn{10}{|c|}{ Titanium (Ti) } \\
\hline FR1 & $\begin{array}{c}2742.73 \pm \\
348.04\end{array}$ & $\begin{array}{c}2651.9 \\
4\end{array}$ & $\begin{array}{c}3447 . \\
92\end{array}$ & $\begin{array}{c}2720 \pm \\
1.13\end{array}$ & 0.076 & $\begin{array}{c}70- \\
20,000 \therefore\end{array}$ & 0.0 & 0.22 & $<0.0001$ \\
\hline
\end{tabular}




\begin{tabular}{|c|c|c|c|c|c|c|c|c|c|}
\hline FR2 & $\begin{array}{c}2537.37 \pm \\
319.27\end{array}$ & $\begin{array}{c}2489.6 \\
5\end{array}$ & $\begin{array}{c}3147 . \\
54\end{array}$ & $\begin{array}{c}2520 \pm \\
1.14\end{array}$ & & & 0.0 & & \\
\hline \multicolumn{10}{|c|}{ Calcium (Ca) } \\
\hline FR1 & $\begin{array}{c}43200 \pm \\
22200\end{array}$ & 37000 & $\begin{array}{c}87687 \\
.7\end{array}$ & $\begin{array}{c}37700 \pm \\
1.73\end{array}$ & \multirow{2}{*}{0.98} & \multirow{2}{*}{$5000^{\bullet}$} & 100 & \multirow{2}{*}{1.8} & 0.25 \\
\hline FR2 & $\begin{array}{c}44100 \pm \\
27300 \\
\end{array}$ & 32700 & $\begin{array}{c}10307 \\
7 \\
\end{array}$ & $\begin{array}{c}37300 \pm \\
1.79 \\
\end{array}$ & & & 100 & & \\
\hline \multicolumn{10}{|c|}{ Potassium (K) } \\
\hline FR1 & $\begin{array}{c}23200 \pm \\
1980\end{array}$ & 23700 & $\begin{array}{c}26315 \\
.9\end{array}$ & $\begin{array}{c}23100 \pm \\
1.09\end{array}$ & \multirow{2}{*}{0.00019} & \multirow{2}{*}{$\begin{array}{c}50- \\
63,000 \therefore\end{array}$} & $100-0$ & \multirow{2}{*}{1.8} & $<0.0001$ \\
\hline FR2 & $\begin{array}{c}20800 \pm \\
2040\end{array}$ & 20100 & $\begin{array}{c}24705 \\
.4\end{array}$ & $\begin{array}{c}20700 \pm \\
1.10\end{array}$ & & & & & \\
\hline \multicolumn{10}{|c|}{ Iron (Fe) } \\
\hline FR1 & $\begin{array}{c}18100 \pm \\
1730 \\
\end{array}$ & 18100 & $\begin{array}{c}20472 \\
.9 \\
\end{array}$ & $\begin{array}{c}18100 \pm \\
1.10 \\
\end{array}$ & \multirow{2}{*}{0.317} & \multirow{2}{*}{$\begin{array}{c}100- \\
>100,00 \\
0 \therefore\end{array}$} & $100-0$ & \multirow{2}{*}{2.1} & $<0.0001$ \\
\hline FR2 & $\begin{array}{c}18900 \pm \\
3020\end{array}$ & 18600 & $\begin{array}{c}26675 \\
.9\end{array}$ & $\begin{array}{c}18600 \pm \\
1.18\end{array}$ & & & & & \\
\hline
\end{tabular}

Similarly, some sites in FR2 were found to contain heavy metals in levels known to be hazardous to human health. Two residential sites and one community site in FR2 were found to contain uranium levels above the LOD (at $16.1 \mathrm{mg} / \mathrm{kg}$ and $11.54 \mathrm{mg} / \mathrm{kg}$, respectively). These values are in excess of the EPA-recommended SSL, which is $<3$ ppm. Similarly, 26\% of samples from FR2 were found to contain measurable levels of Hg. With an average concentration of $9.42 \mathrm{ppm}$ and a maximum concentration of $10.6 \mathrm{ppm}$, these exceeded the recommended soil standard of 0.3 ppm. Finally, although levels of As were not found in levels higher than the EPA SSL (i.e., 50ppm), it was detected at measurable levels at $29 \%$ of residences on FR2, with a mean of $7.9 \mathrm{mg} / \mathrm{kg}$ and a maximum of $9.77 \mathrm{mg} / \mathrm{kg}$. Natural levels of As range between $0.1-40 \mathrm{mg} / \mathrm{kg}$ [40].

\section{Discussion}

Soil samples from two Rocky Mountain West tribal communities were analyzed to establish 1) preliminary understanding of contamination patterns, 2) any levels of concern and 3) to determine if similar histories of anthropogenic contamination, including hard rock mining, movement and the storage of radioactive materials, and/or weapons testing, resulted in similar patterns of contamination between the two communities [41]. Approximately half of the heavy metals included in the comparison were found to be statistically significantly different between reservations (see Table 1). This variation could be due to several factors such as duration of contamination, difference in environmental remediation between reservations, source of contamination, and regional geochemistry.

Analysis of the samples from this study showed that the majority of natural heavy metal levels, with the exception of $\mathrm{Fe}, \mathrm{Ti}$, and $\mathrm{Ca}$, were above the typical regional concentration of these elements in the soil [44].However, these natural levels rarely rise to those detrimental to human health [42, 43]. Levels of Sr, Rb, and Th in FR1 and FR2 were found to exceed EPA targeted values. These significant concentrations of $\mathrm{Sr}, \mathrm{Rb}$, and $\mathrm{Th}$ in the soils could have resulted from anthropogenic sources, including mining, mismanagement of radioactive waste, and/or military ballistic testing [45-46]. Importantly, these three elements pose a particular health risk to Native American populations, as excess levels can bioaccumulate into local vegetation (i.e., the growing of food, plants consumed or burned for ceremonial use). The levels for Rb were far higher at the FR1 location than that at the FR2 site, and should be further investigated to identify how much is being consumed by each community. $\mathrm{Rb}$ and $\mathrm{Sr}$ are known to be readily absorbed by plants [27,47]; Th, conversely, is not typically bioaccumulated in most plants except for shrubs, grasses, and sage 
brush [46], which unique route of exposure due to the use of sagebrush and sweet grass among Native American populations. Furthermore, inhalation of Th dust is linked to an increase risk of developing lung disease, including lung cancer, as well as cancers of the pancreas and bones [25]. This is especially concerning given that many Western tribal communities (particularly those with a history of hard rock mining) experience disproportionately high cancer rates. $[47,48]$.

Concerning levels of $\mathrm{Pb}$, which are generally attributed to sources such as lead-based paint, ammunition, vehicle solvents, or mine tailings (among others) [49], were found only at one particular sampling site in FR1, the former community center at FR1. The community center was also the site of unusually high $\mathrm{Zn}$ and S levels, which suggested external contamination had taken place. After discussion with members of the community, it was determined that the site had formerly been occupied by a machine shop that was used by for welding, grinding, sanding and other machining operations. It is believed that welding operations involving $\mathrm{Pb}$ solder is what caused the contamination of the soil. Welding on galvanized steel was likely the source of the elevated $\mathrm{Zn}$ concentrations.

Regardless of the source, these high $\mathrm{Pb}$ levels could potentially lead to elevated blood levels in nearby residents (e.g., due to ingesting of soil, windblown particles, or hyper-accumulation in plants) and adverse health outcomes such as neurological, hematological, and reproductive health effects [24]. Follow-up testing revealed that the contamination was within 0.6 meters of the building. However, as a preschool is located in close proximity to the community center, and $\mathrm{Pb}$ is particularly toxic to children, this finding was of immediate concern to the community and advisory board. Further investigation and remediation of the soils surrounding the community center is currently in progress.

Several localized anomalies were also found at FR2 that require further investigation. The concentration of a small amount of heavy metals such as selenium (Se), As, vanadium (V), and uranium (U) made up less than $40 \%$ of total results for the FR2, while only one sample from FR1 was found to contain Se. The minor source of Se may be from the use of steel with high Se or fluxes contaminated with Se is a likely source of the Se low concentrations found in FR1 and FR2. As was found in levels ranging between $6.0-8.0 \mathrm{mg} / \mathrm{kg}$, which is well within the natural levels of $0.1-40 \mathrm{mg} / \mathrm{kg}$; however, these levels were only found at 10 sites out of 34 at the FR2 location. Had As been found consistently throughout sampling, this would likely indicate a naturally-occurring source. Instead, As was found in select samples from both residential and community areas, which suggests that As may stem from other anthropogenic sources, such as the use of fertilizers, insecticides, and herbicides. These levels of As can lead to a series of health concerns such as vomiting, diarrhea, skin disorders and even cancer [40, 41]. Further studies of the extent of As contamination in the soils extends at FR2 should be conducted according to EPA-RCRA method 66 FR 6976. Similarly, FR2 was found to have two soil samples (one in a residential area and another near a preschool building) with traceable amounts of U. Further research should be conducted to determine the source of local contamination.

More troublingly, however, is the finding that $\mathrm{Hg}$ was present in $24 \%$ of all FR2 soil samples, averaging 9.4 $\mathrm{mg} / \mathrm{kg}$. These levels are 30 times the USEPA recommended range of $0.1-0.3 \mathrm{mg} / \mathrm{kg}$ for $\mathrm{Hg}$ in soil [50]. $\mathrm{Hg}$ can originate from several sources, including gold mining, jewelry, household appliances, car parts, and others. Ingestion of Hg-contaminated soil can lead to myriad health issues, including neuromuscular change, tremors, emotional change, and developmental stagnation [51, 52]. No amount of $\mathrm{Hg}$ is safe for the human body; indeed, the longer the duration of exposure, the more severe the effect, and so immediate remediation was recommended to the tribe.

The findings in this study align with the growing body of literature on environmental exposures in tribal communities. Several environmental assessments of tribal populations in the Western United States have found that these communities often experience the effects of environmental contamination due to their proximity to active/abandoned mines, waste disposal sites, and former nuclear test sites [으, $\underline{33}$. Findings from this study, as well as the growing body of literature on issues of environmental contamination and Native Americans, suggest that further research developed in collaboration with individual tribes is needed.

As a community-wide screening survey this study had several limitations, including a relatively small sample size collected at both communities. Additionally, tribal communities are often spread across a wide geographic distance (thousands of square miles in many instances). Recruitment constraints and limited resources meant that samples were not evenly distributed across the neighborhoods within the community and exhaustive of all communities across 
the reservations. This was evidenced by the Ca sample results at FR1, where there was $50,000 \mathrm{mg} / \mathrm{kg}$ difference between the median and maximum values. There are often wide variations in naturally-occurring heavy metals within communities, which likely caused the discrepancies in the sample results. Finally, this study employed the use of an XRF to quantify concentrations of heavy metals within the soil samples. For several elements, the XRF had a high LOD and, as such, a considerable number of elements fell below the LOD. The XRF is a cost-effective screening tool of use in determining areas of high heavy metal concentrations. However, the results from this study indicate that the instrument may not be sensitive enough to conduct a quantitative assessment of certain heavy metals in soil beyond a preliminary screening.

While the XRF has been validated by the EPA for analyzing heavy metals in soil, due to the limitations associated with the XRF's LOD, it is recommended that future environmental studies employ the use of laboratory analysis (i.e., ICP or AAS) concurrent with or following an initial screening with an XRF. To develop more comprehensive community-wide assessments, a greater sample size will be needed in order to account for the geological variations and minimize the effect such variations may have on the overall results. It may be necessary in future studies to also examine individual neighborhoods separately from the entirety of the tribal community in order to more accurately identify localized areas of high contamination within the community. This lack of generalizability highlights the need for increased environmental studies on tribal lands in order to support the development of protective regulations and improvements in funding levels for contaminated site remediation.

Lastly, this study points to the importance of building relationships and conducting research via the use of CBPR. The fundamental nature of the partnership with tribal stakeholders allowed for tribal members to use their results according to their own preferences and needs. Community and household de-identified results were shared with tribal council at publicly attended meetings, as well as with the tribal environmental and/or health and/or housing departments. Finally, the $\mathrm{CAB}$ and individual participants in the study received results and recommendations for sampling conducted at their homes. Tribal leadership and individual participants retained ownership of their data, which in turn was used to help each tribe determine culturally appropriate solutions that integrated TEK wherever possible. The research team assisted with resources, referrals, and discussion of possible resources, which has already been successfully completed with past radon testing in tribal homes. In FR1, following receipt of lead levels (initial and follow-up testing), tribal leadership chose to block access to the community center with high levels of lead before pursuing further remediation of the contaminated area and biomonitoring of possibly affected community members. Findings from this study were therefore used by the tribal leadership to enact real, lasting changes for the betterment of the health of their community members.

\section{Conclusion}

The goals for this study included the establishment of a partnership between the tribal communities and the University of Utah research team, a feat that was possible with the successful implementation of the CBPR. CBPR allowed for a methodology that promoted tribal ownership of the process, results, and therefore empowerment to conduct any needed mitigation. The second goal was to characterize the presence of heavy metals in soil and compare levels between communities. Results indicated that $100 \%$ of all soil samples taken and analyzed for Th and Sr from the FR1 and FR2 sites were above the targeted levels, with the samples from the FR1 site, on average, being higher than that of the samples from the FR2 site. Likewise, $\mathrm{Pb}$ and $\mathrm{Rb}$ samples were also higher in concentration in FR1. A clear understanding of naturally occurring heavy metals in each area is needed to determine contamination along with a more comprehensive overview of contamination sources and how localized areas may differ from each other. Even with similar environmental contamination and historical repression, no two reservations should be expected to have the same type and levels of soil contamination. It is suggested that further analysis of both tribal communities needs to be conducted for a more accurate and comprehensive soil assessment. 


\section{Acknowledgments}

The authors would like to thank the tribal communities for their participation in this study.

\section{References}

1. Adakai, M.S.-R., M; Xu, F; Aseret-Manygoats, T; Allison, M; Greenlund, KJ; Barbour, KE, Health Disparities Among American Indians/Alaska Natives - Arizona, 2017. US National Library of Medicine National Institutes of Health, 2018.

2. Natives, T.F.H.P.f.A.I.a.A., Indian Health Services - Fact Sheet: Disparities, U.S.D.o.H.a.H. Services, Editor. 2019.

3. Lewis, J., J. Hoover, and D. MacKenzie, Mining and Environmental Health Disparities in Native American Communities. Current environmental health reports, 2017. 4(2): p. 130-141. doi: 10.1007/s40572-0170140-5

4. EPA, Hazardous Waste Releases on Indian Land: Beginning the Superfund Process. 1989: National Service Center for Environmental Publications.

5. Brook, D., Environmental Genocide: Native Americans and Toxic Waste. The American Journal of Economics and Sociology, 1998. 57(1): p. 105-113.

6. Blake JM, Avasarala S, Artyushkova K, et al. Elevated Concentrations of $\mathrm{U}$ and Co-occurring Metals in Abandoned Mine Wastes in a Northeastern Arizona Native American Community. Environ Sci Technol. 2015;49(14):8506-8514. doi:10.1021/acs.est.5b01408

7. Wyoming, S.o., Wyoming Minerals. Wyoming State Geological Survey, 2020.

8. Vhahangwele, M.K., L. Muedi, Environmental Contamination by Heavy Metals. 2018.

9. McKinley, C.E., Ka'apu, K., Miller Scarnato, J., Liddell, J. (2020) Cardiovascular Health among U.S. Indigenous Peoples: A Holistic and Sex-Specific Systematic Review, Journal of Evidence-Based Social Work, 17:1, 24-48, doi: 10.1080/26408066.2019.1617817

10. Adakai M, S.-R.M., Xu F, Aseret-Manygoats T, Allison M, Greenlund KJ, Barbour KE, Health Disparities Among American Indians/Alaska Natives - Arizona, 2017. US National Library of Medicine National Institutes of Health, 2018.

11. Cobb, N.E., D; King, J, Health behaviors and risk factors among American Indians and Alaska Natives, 2000-2010. Am J Public Health. 2014;104 Suppl 3(Suppl 3):S481-S489. doi:10.2105/AJPH.2014.301879

12. Mayer, B., L. Joshweseoma, and G. Sehongva, Environmental Risk Perceptions and Community Health: Arsenic, Air Pollution, and Threats to Traditional Values of the Hopi Tribe. Journal of Community Health, 2019. 44(5): p. 896-902. doi: 10.1007/s10900-019-00627-8.

13. Sly, P.D., et al., Health Consequences of Environmental Exposures: Causal Thinking in Global Environmental Epidemiology. Annals of Global Health, 2016. 82(1): p. 3-9. doi: 10.1016/j.aogh.2016.01.004

14. Weaver, H.N., Native Americans and cancer risks: moving toward multifaceted solutions. Soc Work Public Health, 2010. 25(3): p. 272-85. doi: 10.1080/19371910903240621

15. Charleston, A.E. and R. Sullivan, Exploring Environmental Health Gaps in Native American Populations. J Environ Health, 2016. 78(9): p. 30-1.

16. Samuel-Nakamura, C.H., Felicia S, Occurrence and Risk of Metal(loid)s in Thelesperma megapotamicum Tea Plant. Plants (Basel). 2019;9(1):21. doi:10.3390/plants9010021

17. Samuel-Nakamura, C.H., Felicia S; Sokolow, Sophie; S. Ali, Abdul-Mehdi; Robbins, Wendie A, Metal(loid)s in Cucurbita pepo in a Uranium Mining Impacted Area in Northwestern New Mexico, USA. Int J Environ Res Public Health. 2019;16(14):2569. doi:10.3390/ijerph16142569 
18. Eggers MJ, Doyle JT, Lefthand MJ, et al. Community Engaged Cumulative Risk Assessment of Exposure to Inorganic Well Water Contaminants, Crow Reservation, Montana. Int J Environ Res Public Health. 2018;15(1):76. Published 2018 Jan 5. doi:10.3390/ijerph15010076

19. Reitze, A.W., Jr., The control of air pollution on Indian reservations. Environmental Law, 2016. 46(4): p. 893. doi: 10.2139/ssrn.2922074

20. Harris, S.G.H., Harper, B.L, Using Eco-Cultural Dependency Webs in Risk Assessment and Characterization of Risks to Tribal Health and Cultures. Environ. Sci. \& Pollut. Res. 2000. 2:91-100.

21. Jardine, C.H.S., Shortreed, J; Craig, L; Krewski, D; Furgal, C; McColl, S, Risk management frameworks for human health and environmental risks. US National Library of Medicine National Institutes of Health, 2003. doi: 10.1080/10937400390208608.

22. Isaac, G., et al., Native American Perspectives on Health and Traditional Ecological Knowledge. Environmental health perspectives, 2018. 126(12): p. 125002-125002. https://doi.org/10.1289/EHP1944

23. McOliver, C.A., et al., Community-based research as a mechanism to reduce environmental health disparities in american Indian and alaska native communities. International journal of environmental research and public health, 2015. 12(4): p. 4076-4100. doi: 10.3390/ijerph120404076.

24. NIOSH, LEAD - health problems caused by lead. CDC 2018.

25. Walker, S., EPA facts about Thorium, in Environmental Protection Agency. 2019.

26. Lenntech. Chemical properties of strontium - Health effects of strontium - Environmental effects of strontium. 2020; Available from: https://www.lenntech.com/periodic/elements/sr.htm.

27. Lenntech, Chemical properties of rubidium - Health effects of rubidium - Environmental effects of rubidium. 2020.

28. Dashner-Titus, E.J., et al., Metal exposure and oxidative stress markers in pregnant Navajo Birth Cohort Study participants. Free radical biology \& medicine, 2018. 124: p. 484-492. doi: 10.1016/j.freeradbiomed.2018.04.579

29. Harmon, M.E., et al., Arsenic association with circulating oxidized low-density lipoprotein in a Native American community. J Toxicol Environ Health A. 2018. 81(13): p. 535-548. doi: 10.1080/15287394.2018.1443860

30. Järup, L., Hazards of heavy metal contamination. British Medical Bulletin, 2003. 68(1): p. 167-182. doi: $10.1093 / \mathrm{bmb} / \mathrm{ldg} 032$.

31. Harris, S. and B.L. Harper, Lifestyles, diets, and Native American exposure factors related to possible lead exposures and toxicity. Environ Res, 2001. 86(2): p. 140-8. 10.1006/enrs.2001.4250

32. Minkler, M., Wallerstein, N., Community based participatory research for health. 2003, San Francisco: Jossey-Bass.

33. Severtson, D.J., L.C. Baumann, and J.A. Will, A Participatory Assessment of Environmental Health Concerns in an Ojibwa Community. Public Health Nursing, 2002. 19(1): p. 47-58. doi: 10.1046/j.15251446.2002.19007.x.

34. EPA, Superfund Soil Screening Guidance.

35. EPA, Heavy Metal Waste Regulation: Which Substances Make Up the RCRA 8 Metals? PEGEX Hazardous Waste Expert, 2015.

36. Shacklette, H.T.B., Josephine G. , Element Concentration in Soils and Other Surficial Materials of the Conterminous United States. U.S. Geological Survey Professional Paper, 1984: p. 63.

37. WHO, Permissible limits of heavy metals in soil and plants (Geneva: World Health Organization). World Health Organization 1996.

38. AIHA. IHSTAT - Statistical Analysis of Health \& Safety Data. Available from: http://ohshub.com/ihstatstatistical-analysis-of-health-safety-data/.

39. Wild, C., The Wilcoxon Rank-Sum Test. Department of Statisitcs University of Auckland, 1997. 2020.

40. CDC, Arsenic Factsheet. National Biomonitoring program, 2017. 
41. Mamtani, R.S., Penny; Dawood, Ismail; Cheema, Sohaila. Metals and Disease: A Global Primary Health Care Perspective. Journal of Toxicology, 2011. doi: 10.1155/2011/319136

42. Li, C., Zhou, K., Qin, W., Tian, C., Qi, M., Yan X., Han, W. (2019) A Review on Heavy Metals Contamination in Soil: Effects, Sources, and Remediation Techniques, Soil and Sediment Contamination: An International Journal, 28:4, 380-394, DOI: 10.1080/15320383.2019.1592108

43. Wuana, R.A.O., Felix E., Heavy Metals in Contaminated Soils: A Review of Sources, Chemistry, Risks and Best Available Strategies for Remediation. International Scholarly Research Notices, 2011. doi: $10.5402 / 2011 / 402647$

44. Britannica, E., Soil regions of the United States, showing areas covered by soil orders of the U.S. Soil Taxonomy. 2008, Encyclopaedia Britannica.

45. Alesksakhin, R.M. Radioactive contamination as a type of soil degradation. Eurasian Soil Sc. 42, 1386 (2009). https://doi.org/10.1134/S1064229309120096

46. Darko G, Boakye KO, Nkansah MA, et al. Human Health Risk and Bioaccessibility of Toxic Metals in Topsoils from Gbani Mining Community in Ghana. J Health Pollut. 2019;9(22):190602. Published 2019 May 20. doi:10.5696/2156-9614-9.22.190602

47. Toxicological Profile for Strontium. Agency for Toxic Substances and Disease Registry.

48. Feemster, R. Wind River Indian Reservation study ties cancer to uranium site. 2014.

49. Porter CM, Wechsler AM, Naschold F, et al. Assessing health impacts of home food gardens with Wind River Indian Reservation families: protocol for a randomised controlled trial. BMJ Open 2019;9:e022731. doi: 10.1136/bmjopen-2018-022731

50. Lead Fact Sheet. CDC, 2013.

51. Balentine, B.L.W., Everett; Solomon, C., Permissible limit for metals. Metal limits.

52. EPA, Health Effects of Exposures to Mercury. 2020.

53. Qin, J.Z., Xuemei; Hao, Yaqiong; Wang, Qi; Fu, Haihui; Yu, Hongjin, Mercury in soil, vegetable and human hair in a typical mining area in China: Implication for human exposure. Journal of Environmental Science, 2017. doi:10.1016/j.jes.2017.05.018

54. Credo, J.e.a., Quantification of Elemental Contaminants in Unregulated Water across Western Navajo Nation. International Journal of Environmental Research and Public Health — Open Access Journal, 2019. 16: p. 2727. doi: 10.3390/ijerph16152727 